\title{
Patrimônio Geomineiro em Diamantina (MG)
}

\author{
Geomoning Heritage in Diamantina (MG)
}

\author{
João Antônio Motta Neto \\ Mestre em Ciência do Solo, Docente do Instituto Federal \\ do Norte de Minas Gerais, Campus Diamantina \\ joao.motta@ifnmg.edu.br
}

\begin{abstract}
Resumo
A região de Diamantina (MG) vem desde o século XVIII convivendo com a mineração do diamante, o que confere à região características muito peculiares. Durante séculos a exploração de diamantes provocou alterações na paisagem, o que pode ser constatado nos diversos sítios geomineiros existentes. Nestes sítios podem ser observadas alterações provocadas no relevo, além da presença de benfeitorias. Verifica-se também uma gastronomia identitária, topônimos, ações institucionais em curso e diversos aspectos da cultura regional, o que pode ser entendido como um verdadeiro patrimônio geomineiro regional. Objetivando sistematizar aspectos deste patrimônio geomineiro, desenvolveu-se este trabalho que encontrou um rico mosaico de aspectos relacionados a este patrimônio. Processos erosivos, a expansão imobiliária e a inexistência de políticas públicas que estimulem a geoconservação aparecem como ameaças a este patrimônio. Por outro lado, vislumbra-se grande potencial de uso científico, educativo e turístico, através do geoturismo, o que pode servir ao fortalecimento deste vetor de desenvolvimento regional.
\end{abstract}

Palavras-chave: Patrimônio; Mineração; Diamante; Diamantina.

\begin{abstract}
The region of Diamantina (MG) has been living with diamond mining since the 18th century, which gives the region very peculiar characteristics. For centuries the exploitation of diamonds has caused changes in the landscape, which can be seen in the various existing geomining sites. In these sites can be observed alterations produced in the relief, besides the presence of buildings. There is also identity gastronomy, toponyms, ongoing institutional actions and various aspects of the regional culture, which can be understood as a true regional geomining heritage. Aiming to systematise aspects of this geomining heritage, this work was developed that found a rich mosaic of issues related to this heritage. Erosive processes, real estate expansion and the lack of public policies that stimulate geoconservation appear as threats to this heritage. On the other hand, there is an excellent potential for scientific, educational and tourist use through geotourism, which can serve to strengthen this regional development vector.
\end{abstract}

Keywords: Heritage; Mining; Diamond; Diamantina.

\section{INTRODUÇÃO}

A influência da ação humana sobre o meio físico (hidrosfera, geosfera e atmosfera) vem sendo discutida e estudada, sendo inequívoco o entendimento desta influência como uma força transformadora de ambientes, conferindo ao ser humano a qualidade de agente geológico e geomorfológico (CASTRO, 2005; SILVA; HORN FILHO, 2014). Neste sentido, a região de Diamantina (MG) encontra-se situada na Serra do Espinhaço Meridional, onde desde meados do século XVIII existem atividades minerárias, com destaque para a mineração do diamante que vem imprimindo topônimos e feições culturais, econômicas e ambientais de modo pronunciado na região (SANTOS, 1976; DEUS; NOGUEIRA, 1993; 
SAINT-HILAIRE, 2004; MARTINS, 2014).

A Serra do Espinhaço pode ser caracterizada como um conjunto de terras altas com extensão aproximada de $1.400 \mathrm{~km}$, nascendo na região central de Minas Gerais e terminando no extremo norte da Bahia. É dividida em Espinhaço Meridional, Setentrional e Chapada Diamantina (ALMEIDAABREU, 1993).

Ao longo destes quase três séculos de existência a exploração de diamantes, seja através do garimpo tradicional ou do garimpo mecanizado, provocou notáveis alterações na paisagem regional, o que pode ser constatado nos diversos sítios geomineiros (SÁNCHEZ RODRÍGUEZ, 2010; PÉREZAGUILAR et al, 2013; BRILHA, 2016) que ainda permanecem como testemunhos históricos. A supressão da cobertura vegetal e atividades de caça para a alimentação dos garimpeiros causaram a redução nas populações de mamíferos, aves, insetos, dentre outros (SILVA et al., 2005), sendo estes fatos analogamente relatados por Matta (2006), ao estudar a atividade garimpeira na Chapada Diamantina (BA).

Com relação ao meio físico também houve modificações na paisagem local como consequência da implantação de garimpos às margens de córregos e rios (aluvião), nas partes secas mais elevadas dos terrenos (garimpos de grupiara) ou em túneis e galerias. Observando áreas garimpadas na Chapada Diamantina (Bahia), Nolasco e Macedo (2005) identificaram as principais feições dos registros sedimentares garimpeiros, classificando-os como indícios de garimpo (ruínas, obras, artefatos e fragmentos), depósitos com limite superfícies exumadas, depósitos de estéril e rejeitos, assoreamento de corpos d'água, além da presença de construções basal com superfície erosiva contínua e cicatrizes (montoeiras, damas, pequenas depressões e marcas de utensílios e explosões).

Sob ótica distinta, tais alterações provocadas na paisagem podem ser consideradas como um patrimônio geomineiro, visto que compreendem vestígios de atividades mineiras pretéritas, com reconhecido valor histórico, cultural e social, constituindo assim uma paisagem cultural geomineira, resultado da interação das operações técnicas realizadas com o meio natural que produziu alterações geoquímicas e morfológicas nos terrenos explorados (MARCHÁN; SÁNCHEZ, 2013).

López-Garcia et al. (2011) ao analisarem a situação atual de sítios mineiros abandonados na Espanha, argumentam que apesar da degradação ambiental gerada pela atividade minerária, alguns locais deveriam ser reconhecidos como patrimônio geológico, pois agregam valores científico, educacional e turístico.

Desta forma objetivou-se com este trabalho sistematizar diversos aspectos relacionados ao patrimônio geomineiro regional (sítios, técnicas, povoamentos, gastronomia, etc..) além das alterações na paisagem provocadas pela extração do diamante na região de Diamantina (MG). 


\section{MATERIAIS E MÉTODOS}

Este trabalho foi realizado no município de Diamantina (MG) no período compreendido entre os meses de outubro de 2017 a julho de 2018, sendo os estudos concentrados nas áreas onde historicamente houve maior concentração da atividade garimpeira (CHAVES; MENEGHETTI FILHO, 2002), ou seja, o eixo dos distritos São João da Chapada - Guinda e o entorno do distrito de Extração, além de uma porção do Rio Jequitinhonha. A princípio foi realizada a leitura e análise de referências bibliográficas, que ajudaram no entendimento dos cenários observados, sendo que posteriormente foram visitados os locais de interesse.

Em cada lavra visitada foram observados o contexto histórico, geológico, pedológico, geomorfológico, hídrico e mineiro, realizando-se os respectivos registros. Estes locais foram georreferenciados por meio de um navegador GPS (Garmin GPSMAP 64s), sendo os dados descarregados no software Google Earth Pro®, possibilitando uma ampla visão espacial dos sítios encontrados.

A partir daí levantou-se quais registros tecnogênicos ligados ao processo de transformação da paisagem foram encontrados nestes locais, buscando-se associar estes registros aos métodos de lavra utilizados no passado. As terminologias utilizadas foram adaptadas a partir de Nolasco (2002).

Também foram sistematizadas informações a respeito de outros aspectos relacionados ao patrimônio geomineiro regional, como por exemplo a gastronomia identitária na forma de comidas e bebidas.

\section{RESULTADOS}

\subsection{Inventariação de lavras}

No decorrer dos trabalhos de campo, foram inventariados 13 sítios geomineiros, estando alguns deles ainda sofrendo a atividade garimpeira de maneira artesanal até os dias de hoje. O nome e a localização destes sítios estão descritos no quadro 1 e na Figura 1.

Os sítios geomineiros estudados foram classificados sob uma tipologia, que está relacionada à posição do sítio no relevo, a seguir:

a) Lavras de serras (terrenos altos e secos): áreas localizadas em cotas mais altas do terreno, normalmente em colúvios formados pelo processo de pedogênese;

b) Lavras de gretas e frinchas: locais onde os afloramentos de quartzitos tiveram suas fraturas preenchidas com sedimentos (cascalho, areia, etc...), transportados pela erosão e aprisionados nestes locais;

c) Lavras de aluvião: situadas nas margens dos cursos dágua, onde são formados depósitos sedimentares normalmente de matriz arenosa. 
Quadro 1 - Sítios geomineiros inventariados.

\begin{tabular}{cc}
\hline Nome & Localização \\
\hline Califórnia (Pedra Morena) & Sopa \\
Caldeirão & Sopa \\
Barro & São João da Chapada \\
Chapada Velha & São João da Chapada \\
Mungongo & Guinda \\
Lavrinha & Guinda \\
Diamante Vermelho & Guinda \\
Entorno da Barragem Zé Pedro & Extração \\
Boa Vista & Extração \\
Tanque da Serra (Bom Sucesso) & Extração \\
Mendanha & Rio Jequitinhonha \\
Acaba Mundo & Rio Jequitinhonha \\
Lavra do Mato & Rio Jequitinhonha \\
\hline
\end{tabular}

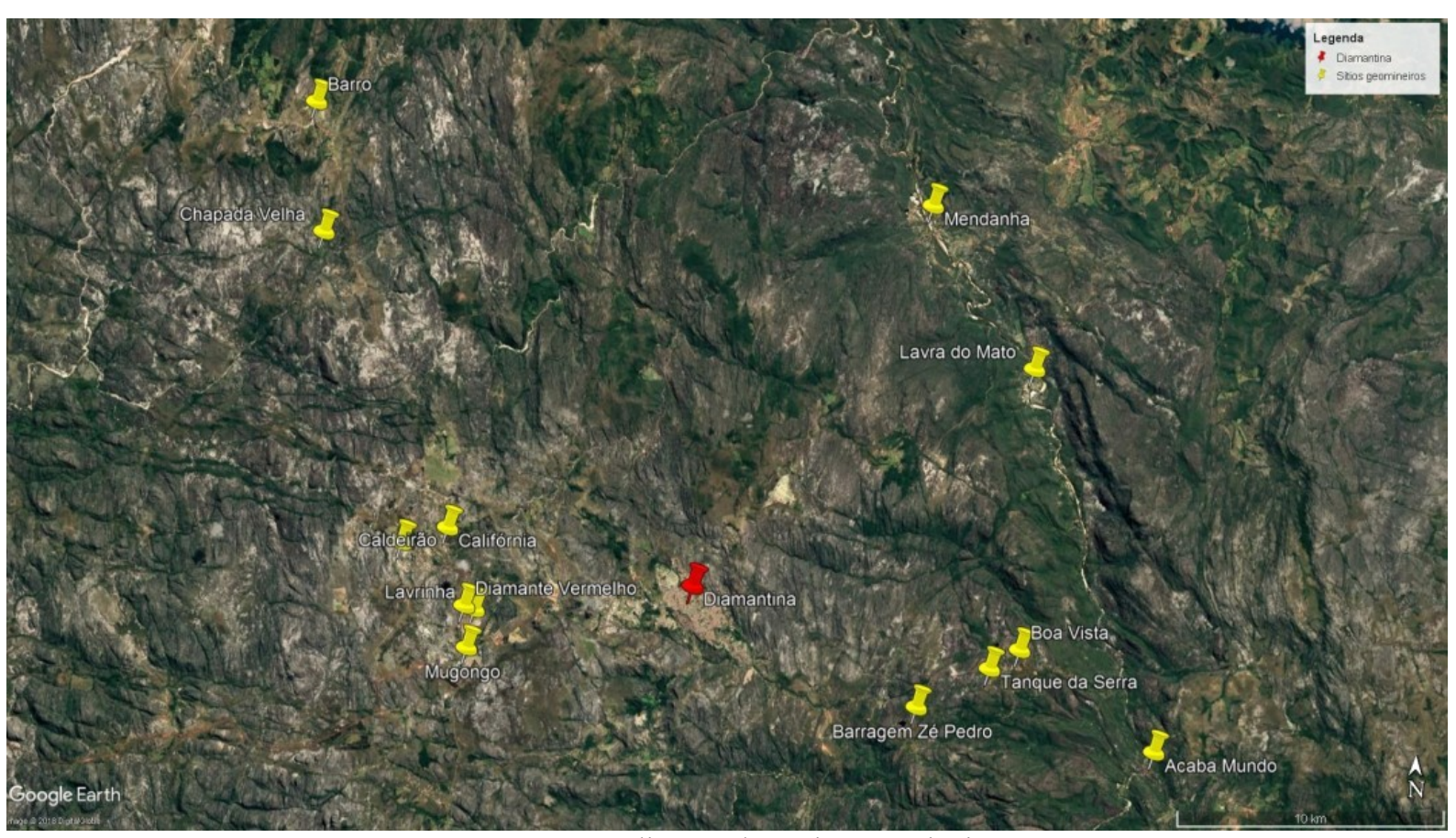

Figura 1 - Localização dos sítios geomineiros. Fonte - Google Earth Pro ${ }^{\circledR}$.

\subsection{Técnicas de lavra identificadas}

Nestes sítios geomineiros foram identificados vestígios das técnicas de lavra utilizadas no passado. As feições tecnogênicas observadas atualmente foram a chave para a identificação destes vestígios, além de depoimentos de moradores e antigos garimpeiros. 
De acordo com as observações foi possível inferir que as feições encontradas foram desenvolvidas a partir de uma, ou da interação entre diversas técnicas de lavra, conforme descrito abaixo.

a) Desmonte seco e hidráulico dos barrancos, formando cavas e cicatrizes;

b) Separação mecânica de matacões através de catação, formando as montoeiras;

c) Peneiramento de cascalhos, formando pequenos montes;

d) Lavagem do cascalho nas bicas, gerando os depósitos chamados "rabos de bica" que se assemelham a pequenos leques aluviais;

e) Sucção mecanizada de material (areia, sedimentos e cascalhos) através de bombas de garimpo, formando as catas.

\subsection{Registros tecnogênicos}

Os principais registros encontrados a campo foram classificados de acordo com a terminologia proposta por Nolasco (2002), a seguir.

\section{a) Indícios de garimpo}

São ruínas de benfeitorias (muros, paredes, alicerces), obras (bicames, pequenas barragens, etc..) e artefatos (ferramentas, grelhas, bicas, encanamentos, etc...), conforme exemplo na Figura 2.

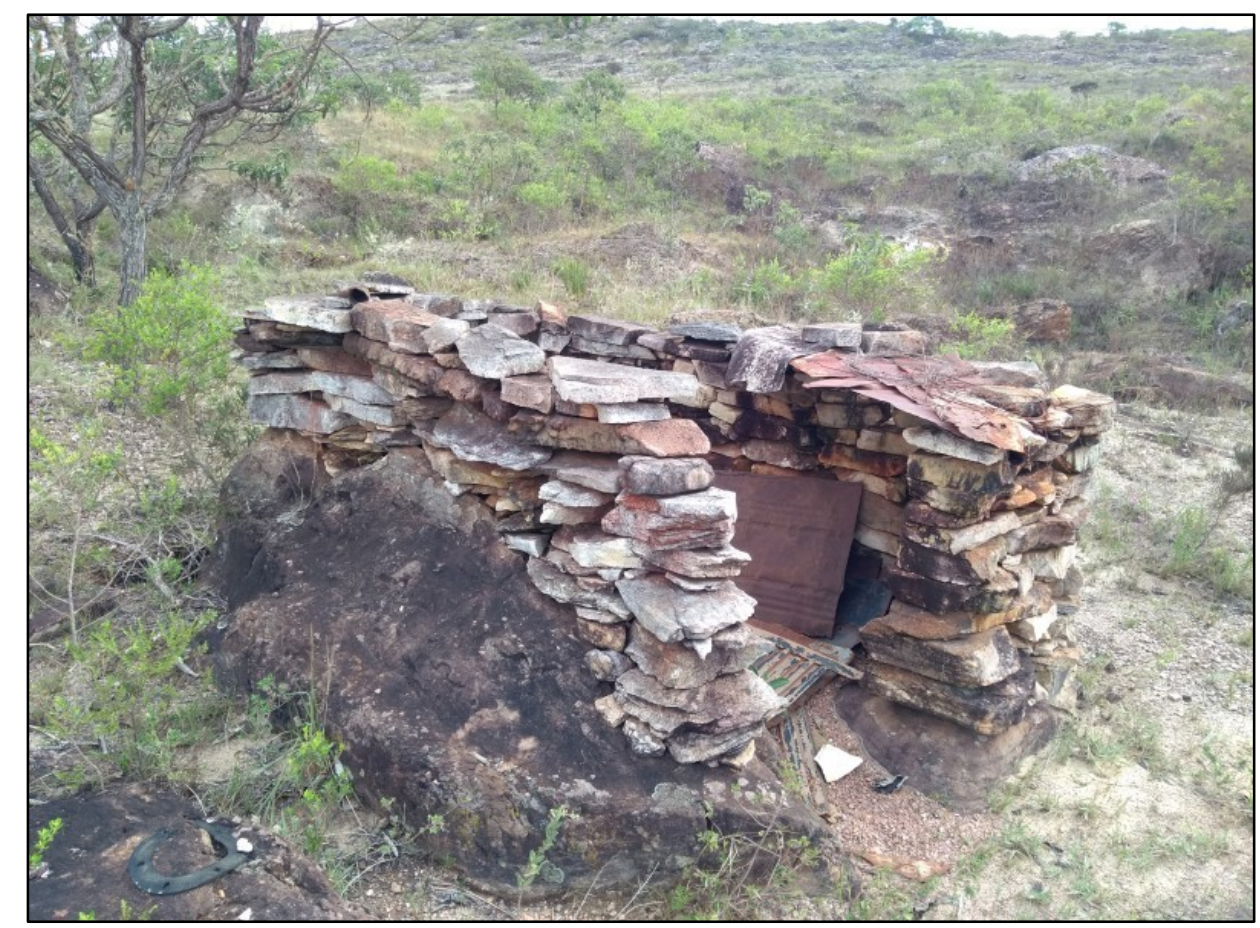

Figura 2 - Ruína de antigo abrigo.

Fonte - Motta Neto, 2018 


\section{b) Depósitos}

São estruturas sedimentares de diversos formas e volumes, formadas a partir de processos de lavra e beneficiamento, podendo ser divididos como construídos e induzidos.

- Montoeiras (paiol de pedras);

- Rabos de bica que formam pequenos estruturas sedimentares;

- Montes de cascalhos lavados: diferem das montoeiras devido a menor granulometria dos seus constituintes (Figura 3);

- Dunas de areia originadas do esvaziamento das catas através de sucção das bombas.

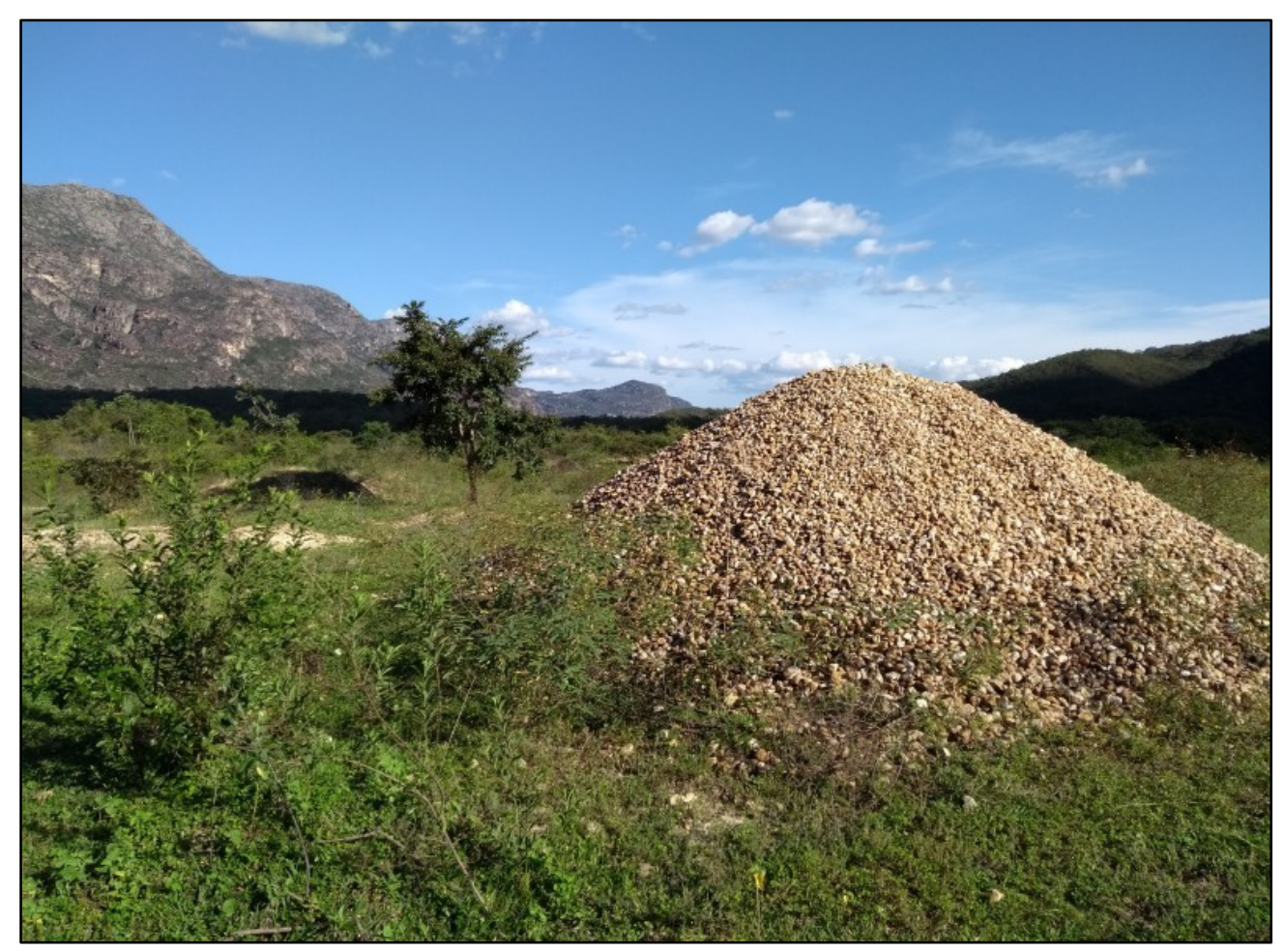

Figura 3 - Monte de cascalhos em lavra de aluvião.

Fonte - Motta Neto, 2018.

\section{c) Cicatrizes}

São caracterizadas pelo esvaziamento de partes do relevo, através dos processos e técnicas de garimpagem. Da mesma forma também podem ser construídas ou induzidas, e comportam-se como fontes de sedimentos que serão depositados em outros locais. Dentre alguns exemplos, pode-se citar: Voçorocas e ravinas (Figura 4); Fraturas esvaziadas (gretas ou frinchas); Canais escavados (para transporte de água); Barrancos (limite da frente da lavra); Damas: barrancos residuais onde o horizonte $\mathrm{C}$ do solo permanece exposto; Catas abertas pela sucção mecanizada; Rochas exumadas; Pequenas depressões; Marcas de utensílios e explosões. 


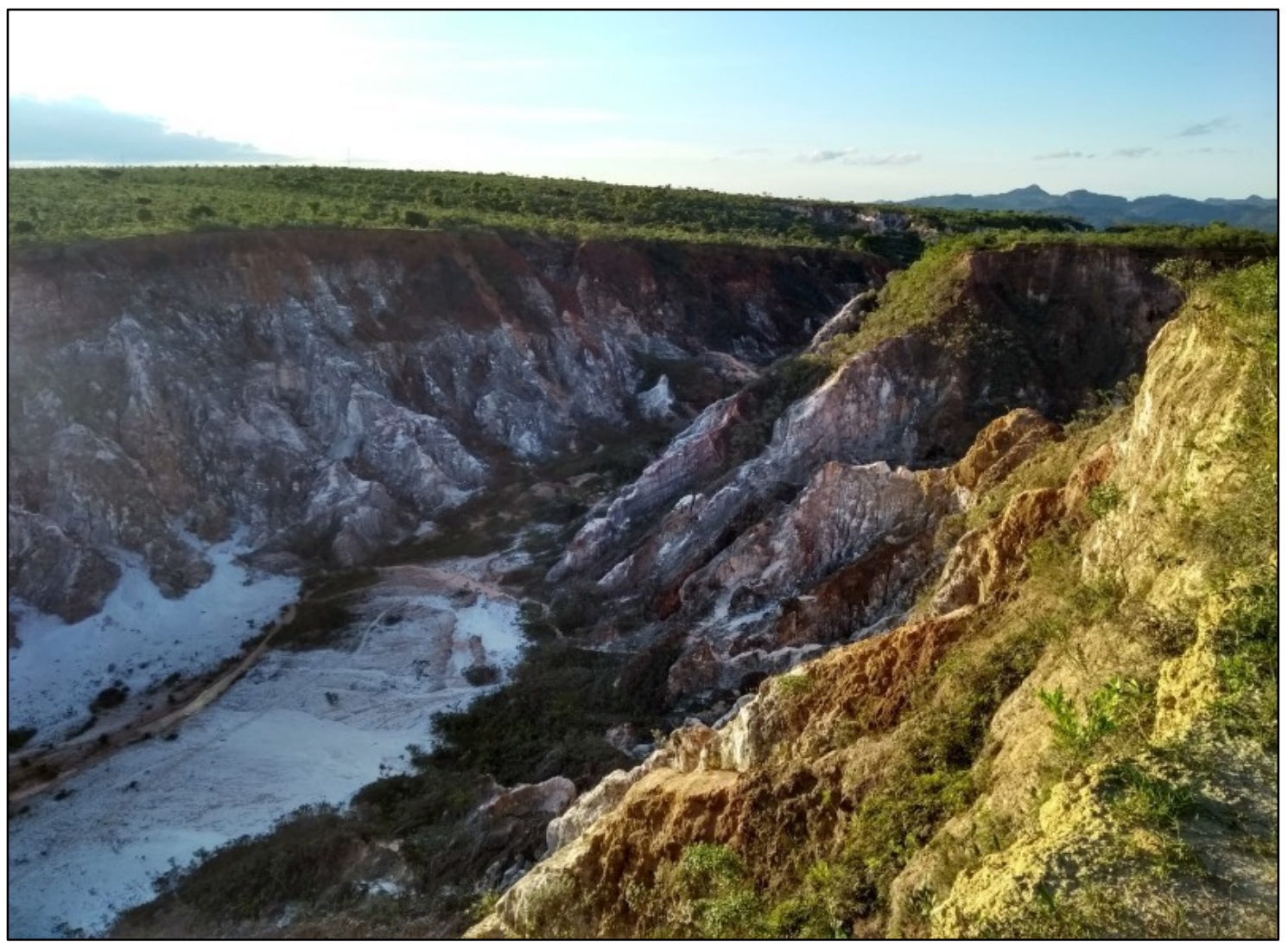

Figura 4 - Voçoroca na Lavra do Barro.

Fonte - Motta Neto, 2018.

Nos quadros abaixo estão descritas as técnicas de lavra encontradas, seguido dos registros tecnogênicos produzidos por estas técnicas, além das modificações observadas na vegetação e nos recursos hídricos em cada tipo característico de lavra: Serras, Gretas e Frinchas, Aluvião (Figuras 5, $6,7)$.

Quadro 2. Registros tecnogênicos observados na Lavra do Diamante Vermelho (Serras).

\begin{tabular}{|c|c|c|c|}
\hline Método/técnica de lavra & Cicatrizes & Depósitos & Vegetação \\
\hline $\begin{array}{l}\text { Desmonte seco e } \\
\text { hidráulico }\end{array}$ & $\begin{array}{l}\text { Voçorocas. } \\
\text { Barrancos (limite da frente de } \\
\text { desmonte). } \\
\text { Exumação do conglomerado } \\
\text { diamantífero. }\end{array}$ & $\begin{array}{l}\text { Acúmulo de sedimentos } \\
\text { mais finos no fundo da } \\
\text { voçoroca. }\end{array}$ & \multirow{6}{*}{$\begin{array}{c}\text { Supressão da } \\
\text { vegetação original. } \\
\text { Aparecimento de } \\
\text { sucessão secundária } \\
\text { sobre os depósitos. }\end{array}$} \\
\hline $\begin{array}{l}\text { Separação mecânica de } \\
\text { matacões (catação) }\end{array}$ & - & Montoeiras de matacões. & \\
\hline Peneiramento & - & Montes de cascalhos. & \\
\hline Barragens de pedras & - & $\begin{array}{l}\text { Acúmulo de sedimentos no } \\
\text { fundo dos depósitos. }\end{array}$ & \\
\hline $\begin{array}{c}\text { Canal para transporte de } \\
\text { água }\end{array}$ & Pequenos canais escavados. & - & \\
\hline Vestígios & Abrigo de pedras & - & \\
\hline
\end{tabular}




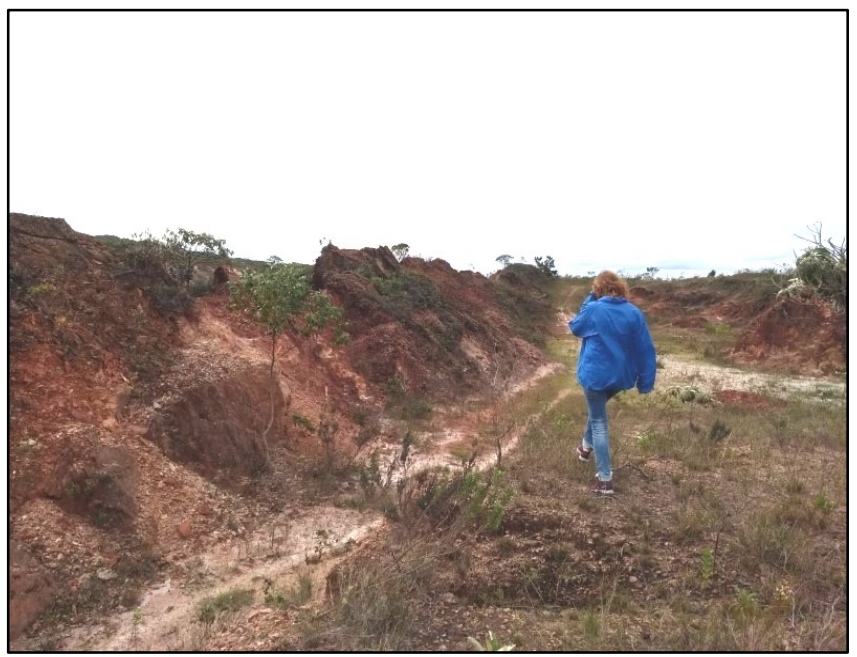

Figura 5 - Voçoroca aberta pelo garimpo.

Fonte - Motta Neto, 2018.

Quadro 3. Registros tecnogênicos observados na Lavra Tanque da Serra (Gretas e Frinchas).

\begin{tabular}{|c|c|c|c|}
\hline Método/técnica de lavra & Cicatrizes & Depósitos & Vegetação \\
\hline $\begin{array}{l}\text { Separação mecânica de } \\
\text { matacões (catação) }\end{array}$ & $\begin{array}{c}\text { Fraturas abertas } \\
\text { esvaziadas. } \\
\text { Exumação do } \\
\text { conglomerado } \\
\text { diamantífero. }\end{array}$ & $\begin{array}{l}\text { Montoeiras de matacões e cascalhos próximo às } \\
\text { fraturas. }\end{array}$ & \\
\hline $\begin{array}{l}\text { Canal para transporte de } \\
\text { água }\end{array}$ & - & $\begin{array}{l}\text { Terraço originado da deposição por contenção de } \\
\text { sedimentos no interior do canal } \\
\text { (aproximadamente } 500 \text { metros de extensão). }\end{array}$ & \multirow{2}{*}{$\begin{array}{c}\text { Aparecimento } \\
\text { de sucessão } \\
\text { secundária } \\
\text { sobre os } \\
\text { depósitos. }\end{array}$} \\
\hline Peneiramento & - & $\begin{array}{l}\text { Montes de cascalhos lavados, sendo alguns } \\
\text { retrabalhados atualmente. }\end{array}$ & \\
\hline
\end{tabular}

Lavagem do cascalho nas bicas

Barragem de pedras
Rabos de bica semelhantes a pequenos leques aluviais.

Montes de cascalhos lavados, sendo alguns retrabalhados atualmente.

Pequeno acúmulo de sedimentos mais finos.

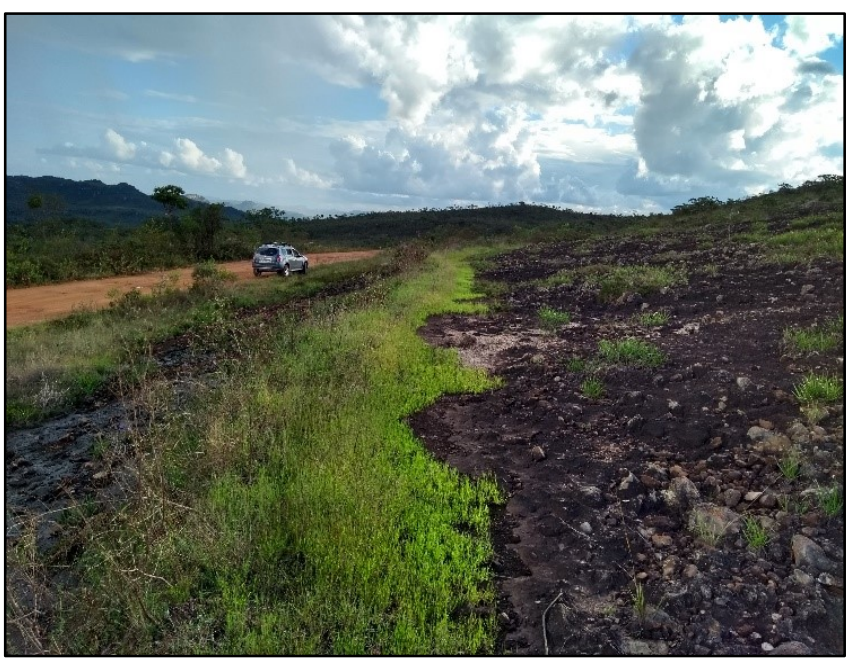

Figura 6 - Canal de água assoreado.

Fonte - Motta Neto, 2018 
Quadro 4. Registros tecnogênicos observados na Lavra do Mato (Aluvião).

\begin{tabular}{|c|c|c|c|c|}
\hline Método/técnica de lavra & Cicatrizes & Depósitos & Recursos Hídricos & Vegetação \\
\hline Desmonte hidráulico & $\begin{array}{l}\text { Barrancos (limite } \\
\text { da frente de } \\
\text { desmonte). }\end{array}$ & $\begin{array}{c}\text { Acúmulo de } \\
\text { sedimentos mais finos } \\
\text { na planície aluvial. }\end{array}$ & $\begin{array}{l}\text { Aumento da planície } \\
\text { aluvial do Rio } \\
\text { Jequitinhonha, mas com } \\
\text { relevo mais irregular. }\end{array}$ & \multirow{5}{*}{$\begin{array}{c}\text { Supressão da } \\
\text { vegetação original. } \\
\text { Aparecimento de } \\
\text { sucessão } \\
\text { secundária sobre os } \\
\text { depósitos. }\end{array}$} \\
\hline $\begin{array}{c}\text { Separação mecânica de } \\
\text { matacões (catação) }\end{array}$ & - & $\begin{array}{l}\text { Montoeiras de } \\
\text { matacões }\end{array}$ & - & \\
\hline Peneiramento & - & $\begin{array}{l}\text { Montes de areia e } \\
\text { cascalhos }\end{array}$ & - & \\
\hline $\begin{array}{l}\text { Lavagem de material nas } \\
\text { bicas }\end{array}$ & - & Rabos de bica & - & \\
\hline $\begin{array}{c}\text { Sucção mecanizada de } \\
\text { material }\end{array}$ & $\begin{array}{l}\text { Abertura de catas } \\
\text { com posterior } \\
\text { formação de lagoas. } \\
\text { Exumação de } \\
\text { rochas }\end{array}$ & $\begin{array}{c}\text { Dunas de areia } \\
\text { originadas do } \\
\text { esvaziamento da cata. }\end{array}$ & $\begin{array}{c}\text { Pequenas lagoas com alta } \\
\text { turbidez }\end{array}$ & \\
\hline
\end{tabular}

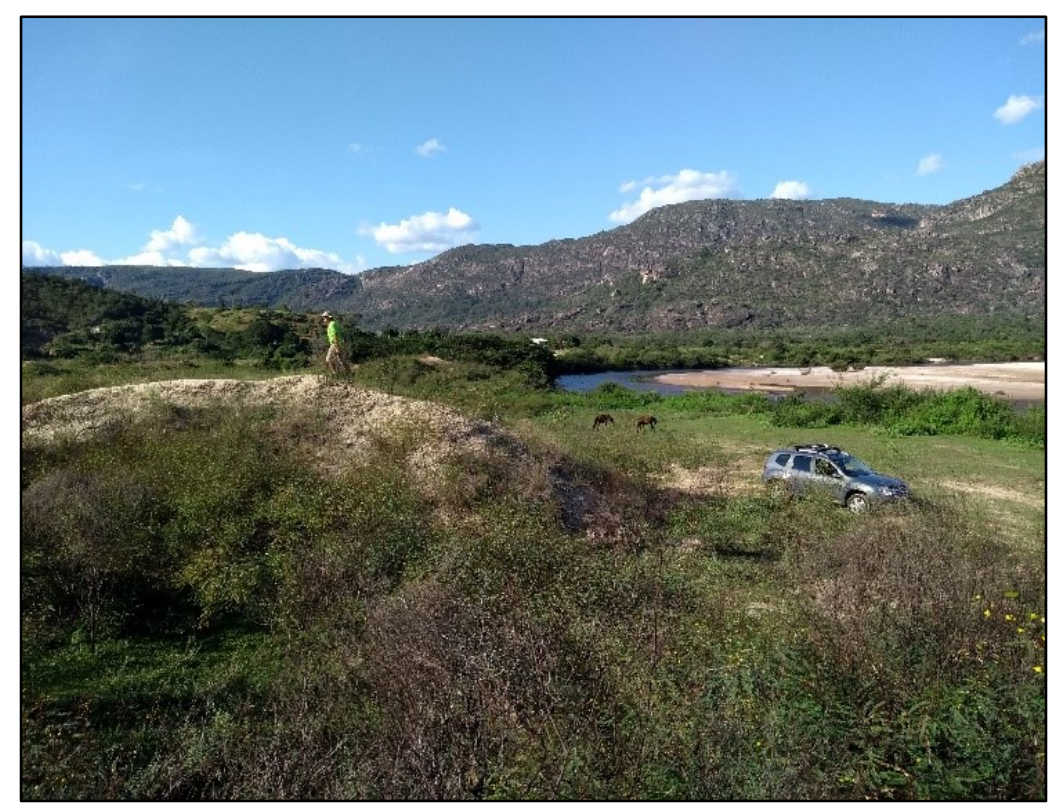

Figura 7 - Lavra do Mato, tendo ao fundo o Rio Jequitinhonha.

Fonte - Motta Neto, 2018.

\subsection{Povoamentos (Chapada Velha e Chácara do Intendente Câmara)}

Foi inventariado um antigo povoado setecentista no distrito de São João da Chapada, conhecido como Chapada Velha, outrora sede de um povoamento civil e também posto militar, restando hoje um conjunto de ruínas remanescentes (RIBEIRO, 2013). Deste local saiu a comunidade que deu origem ao distrito de São João da Chapada em meados do século XIX. Neste povoamento abandonado, hoje pertencente a uma propriedade rural particular, são visíveis várias estruturas, como uma rua calçada, alicerces, muros, uma cadeia com paredes (Figura 8), currais, canais de 
abastecimento de água, sendo rodeado de vestígios de lavras abandonadas.

Da mesma forma, no distrito de Sopa permanece até os tempos atuais a antiga chácara do famoso Intendente Câmara (SANTOS, 1976), hoje uma propriedade particular sendo habitada por um caseiro que cuida do local. A habitação está em um estado de conservação razoável e apresenta diversas ruínas de muros, canais de água e tanques de pedra na área externa (Figura 9).

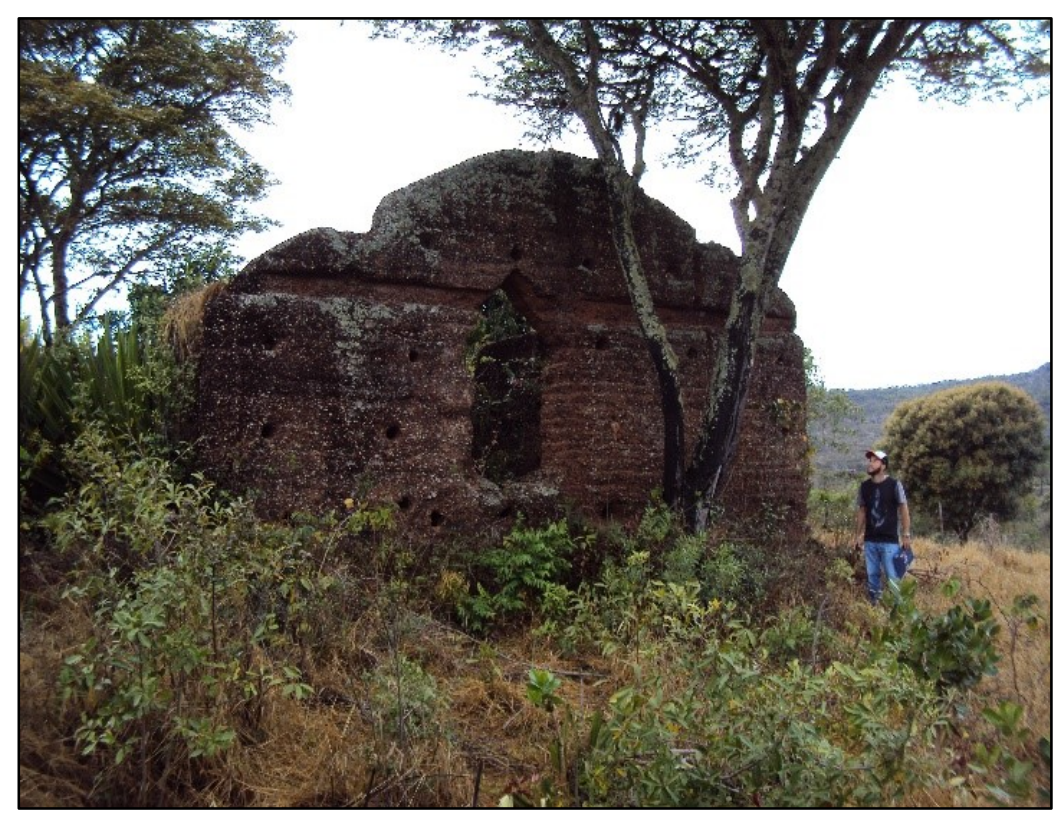

Figura 8 - Ruína da cadeia da Chapada Velha. Fonte - Motta Neto, 2018

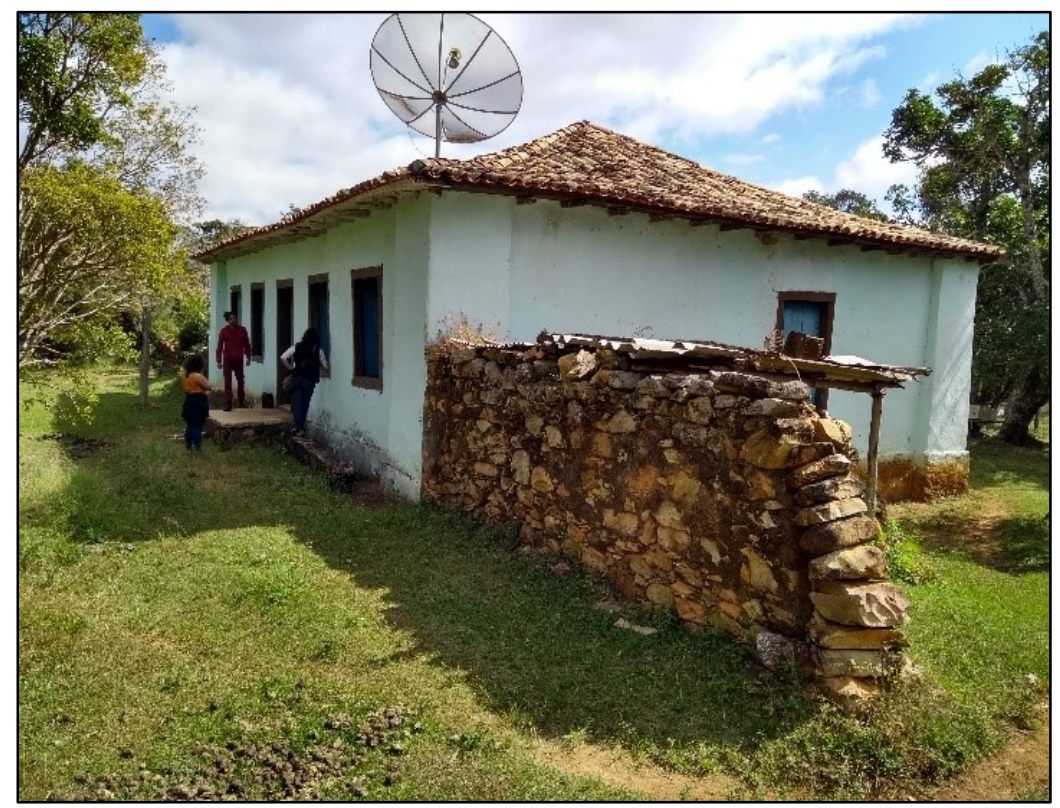

Figura 9 - Chácara do Intendente Câmara. Fonte - Motta Neto, 2018 


\subsection{Identificação da gastronomia identitária geomineira ("geofood")}

Tomando como base o conceito discutido por Vale et al. (2014), dentro da gastronomia diamantinense o prato típico que mais se identifica com a cultura garimpeira é o conhecido "Bambá do Garimpo", uma iguaria a base de costelinha de porco, feijão e couve. Dentro do grupo das bebidas destaca-se a cerveja artesanal "Diamantina Garimpo" e a cachaça "Chibiu do Burgalhau", sendo que chibiu no linguajar garimpeiro significa um diamante muito pequeno.

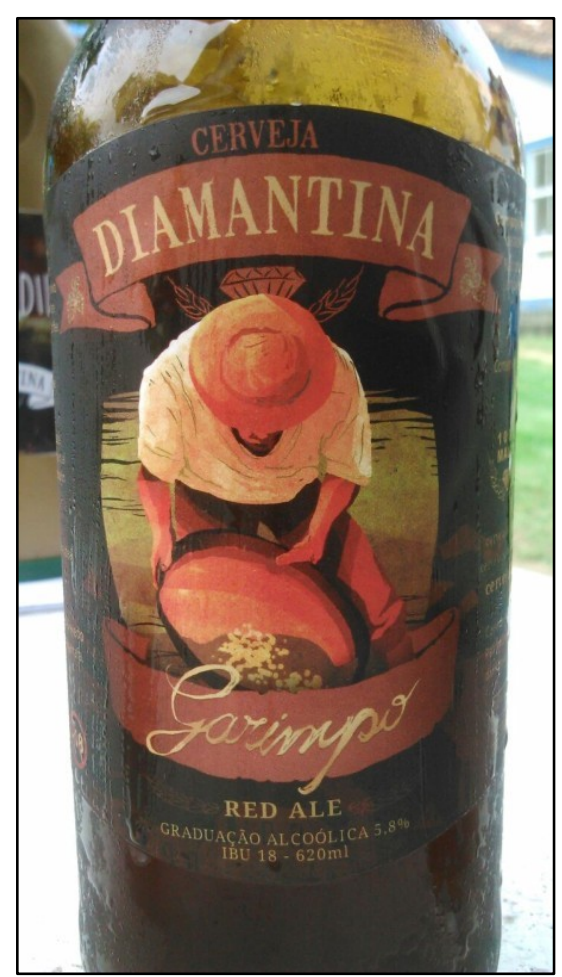

Figura 10 - Cerveja artesanal da região. Fonte - Motta Neto, 2018

\subsection{Avaliação de riscos ao patrimônio geomineiro}

Processos erosivos são constantes e intensos em todas as lavras visitadas. Tal fenômeno advém da fragilidade dos solos da região, de matriz arenosa com muita pedregosidade, além de intensas chuvas, comuns em determinadas épocas do ano. Tal fato contribui para uma contínua alteração da paisagem, perda de solos e assoreamento dos cursos d'água próximos a estes locais.

Em todos os distritos garimpeiros uma visível expansão imobiliária através de loteamentos, vem avançando sobre alguns sítios geomineiros, com a instalação de cercas de arame e até mesmo a construção de edificações e vias de acesso, como é o caso do geossítio SIGEP Lavrinha, no distrito de Guinda (CHAVES; MENEGHETTI FILHO, 2002). 


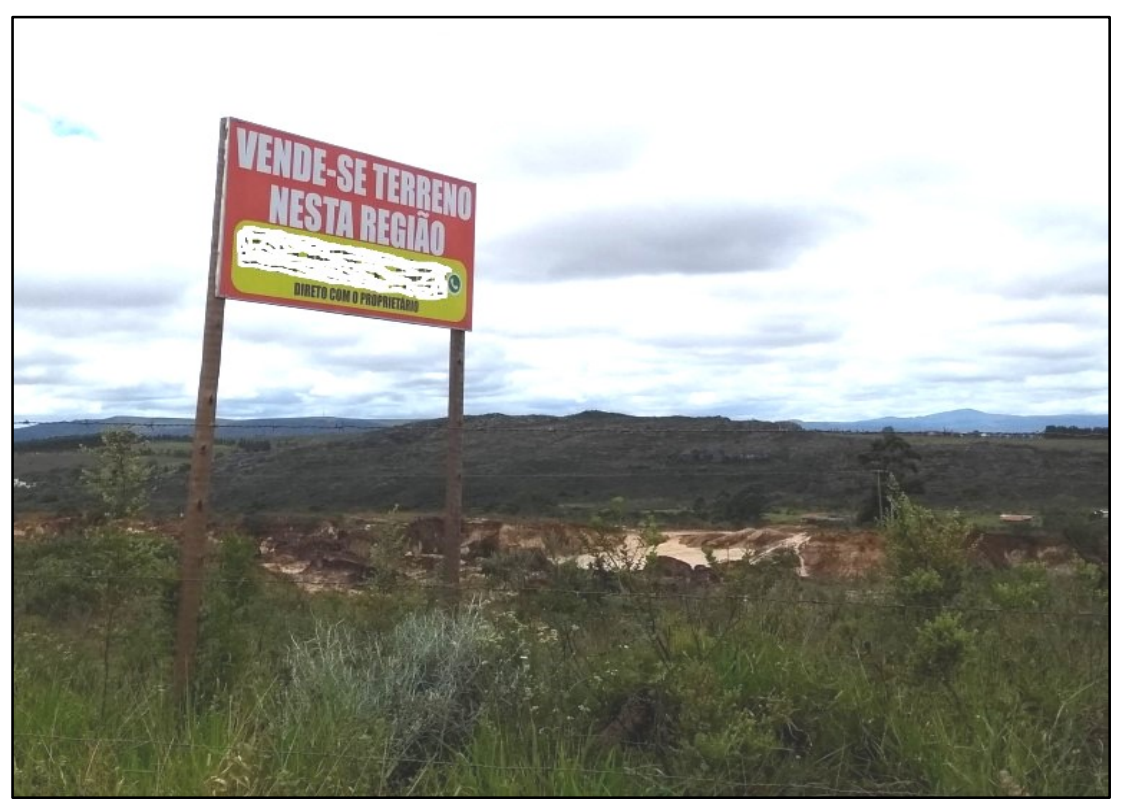

Figura 11 - Comércio de terrenos no geossítio Lavrinha.

Fonte - Motta Neto, 2018.

\section{CONSIDERAÇÕES FINAIS}

Apesar do caráter inicial deste trabalho, foi possível identificar diversos aspectos que demonstram a possibilidade de uma nova leitura da realidade regional calcada no conceito de patrimônio geomineiro. As centenárias lavras diamantíferas abandonadas ou ainda sendo exploradas, os registros tecnogênicos derivados dos processos desenvolvidos nestas lavras, os povoamentos, a gastronomia relacionada ao garimpo, os diversos topônimos existentes, as instituições que vêm atuando na região e diversas formas de expressão da cultura local são alguns exemplos de aspectos que podem servir a construção desta proposta.

Os sítios geomineiros encontrados apresentam enorme potencial de uso científico, educativo e turístico, conforme demonstrado por Kuchenbecker et al. (2016). Mas por outro lado, na ausência de um projeto maior que desenvolva este potencial, estes locais poderão ser somente reconhecidos como áreas degradadas e terrenos inúteis, aspecto também discutido por Beraaouz et al. (2017).

Foram observadas alterações de grande monta principalmente no relevo, vegetação e no ciclo hidrológico, fruto de um processo extrativista histórico. Perdas de solo com consequente assoreamento dos cursos d água, a diminuição da recarga do lençol freático e o aumento na velocidade de escoamento superficial, tem levado a grande dificuldade no reestabelecimento de um novo patamar de equilíbrio dos ciclos biogeoquímicos, visto que diversos processos erosivos continuam ativos. Neste cenário, fica claro a necessidade de intervenção humana para a recuperação destas áreas degradadas, fato constatado por Amaral (2012).

Sendo assim é muito importante que sejam criadas condições que estimulem ações institucionais sobre este tema na região, de modo que sejam criadas políticas públicas que facilitem 
a criação de um novo vetor de desenvolvimento ambiental, social e econômico através da geoconservação e do geoturismo, o que poderia beneficiar principalmente as comunidades locais dos distritos diamantíferos, atualmente com limitados horizontes de melhoria de suas condições de vida.

\section{REFERÊNCIAS}

ALMEIDA-ABREU, P. A. A evolução geodinâmica da Serra do Espinhaço Meridional, Minas Gerais, Brasil. 1993. 150 f. Tese (Doutorado) - Albert-Ludwigs, Universität, Freiburg, Alemanha, 1993.

AMARAL, W. G. Caracterização de áreas em Diamantina (MG) sob diferentes tipos de degradação: substrato, dinâmica da vegetação e paisagem. 2012. 80 f. Dissertação (Mestrado em Ciência Florestal) - Universidade Federal dos Vales do Jequitinhonha e Mucuri, Diamantina, 2012.

BERAAOUZ, M.; MACADAM, J.; BOUCHAOU, L.; IKENNE, M.; ERNST, R.; TAGMA, T.; MASROUR, M. An Inventory of Geoheritage Sites in the Draa Valley (Morocco): a Contribution to Promotion of Geotourism and Sustainable Development. Geoheritage, v. 10, n. 1, p. 1-15, 2017.

BRILHA, J. B. R. Inventory and Quantitative Assessment of Geosites and Geodiversity Sites: a Review. Geoheritage, v. 8, P. 119-134, 2016.

CASTRO, P. T. A. O Tecnógeno e as idéias de Vernadsky. In: CONGRESSO DA ASSOCIAÇÃO BRASILEIRA DE ESTUDOS DO QUATERNÁRIO, 10., 2005, Guarapari. Anais... Guarapari: ABEQUA, 2005. p. 21-26.

CHAVES, M. L. S. C.; MENEGHETTI FILHO, I. Conglomerado Diamantífero Sopa, região de Diamantina, MG: marco histórico da mineração do diamante no Brasil. In: SCHOBBENHAUS, C. Sítios geológicos e paleontológicos do Brasil. Brasília: CPRM, 2002. p. 517-527.

DEUS, J. A. S.; NOGUEIRA, M. Mineração e percepção ambiental na toponímia da mesoregião do Jequitinhonha. In: VIII SIMPÓSIO DE GEOLOGIA DE MINAS GERAIS, 8., 1995, Diamantina. Anais... Diamantina: SBG-IGC/UFMG, 1995. p. 7-8.

KUCHENBECKER, M.; FRAGOSO D. G. C.; SANGLARD J. C. D.; FANTINEL L. M. A utilização de lavras desativadas como laboratórios naturais para ensino de Geociências: exemplos de Diamantina (MG). Terræ Didatica, v. 12, n. 1, p. 56-68, 2016.

LÓPEZ-GARCÍA, J. A.; OYARZUN, R.; ANDRÉS, S. L.; MARTÍNEZ, J. I. M. Scientific, educational, and environmental considerations regarding mine sites and geoheritage: a perspective from SE Spain. Geoheritage, n. 3, p. 267-275, 2011.

MARCHÁN, C.; SÁNCHEZ, A. Consideraciones sobre el patrimonio minero desde la perspectiva de un servicio geológico nacional. Boletim Paranaense de Geociências, v. 70, p. 77-86, 2013.

MARTINS, M. L. Breviário de Diamantina: uma história do garimpo de diamantes nas Minas Gerais (século XIX). 1. ed. Belo Horizonte: Fino Traço, 2014. 431p.

MATTA, P. M. O garimpo na Chapada Diamantina e seus impactos ambientais: uma visão histórica e suas perspectivas futuras. 2006. 187 f. Dissertação (Mestrado em Engenharia Ambiental Urbana) - Escola Politécnica, Universidade Federal da Bahia, Salvador, 2006. 
NOLASCO, M. C. Registros geológicos gerados pelo garimpo, Lavras Diamantinas - Bahia. 2002. 363 f. Tese (Doutorado em Ciências) - Universidade Federal do Rio Grande do Sul, Porto Alegre, 2002.

NOLASCO, M. C.; MACEDO, A. Registros geológicos garimpeiros a diamantes - chaves de identificação de cicatrizes erosivas e depósitos tecnogênicos. In: CONGRESSO DA ASSOCIAÇÃO BRASILEIRA DE ESTUDOS DO QUATERNÁRIO, 10., 2005, Guarapari. Anais... Guarapari: ABEQUA, p. 1-7, 2005.

PÉREZ-AGUILAR, A.; JULIANI, C.; BARROS, E. J.; ANDRADE, M. R. M.; OLIVEIRA, E. S.; BRAGA, D. A.; SANTOS, R. O. Archaeological Gold Mining Structures from Colonial Period Present in Guarulhos and Mairiporã, São Paulo State, Brazil. Geoheritage, v. 5, p. 87-105, 2013.

RIBEIRO, L. Cativos do Diamante. Etnoarqueologia, Garimpo e Capitalismo. Revista Espinhaço, v. 2, n. 1, p. 153-167, 2013.

SAINT-HILAIRE, A. de. Viagem pelo Distrito dos Diamantes e litoral do Brasil. PENNA, L. de A. Trad. Belo Horizonte: Itatiaia, 2004. 452p.

SÁNCHEZ RODRÍGUEZ, A. Estudio del patrimonio minero de Extremadura. In: FLORIDO, P.; RÁBANO, I. (Eds.). Una visión multidisciplinar del patrimonio geológico y minero. Cuadernos del Museo Geominero: $n^{\circ}$ 12. Madrid: Instituto Geológico y Minero de España, 2010, p. 3-33.

SANTOS, J. F. Memórias do Distrito Diamantino. 4 ed. Belo Horizonte: Itatiaia, 1976. 338p.

SILVA, A. C.; PEDREIRA, L. S. F.; ALMEIDA-ABREU, P. A. A Serra do Espinhaço Meridional: paisagens e ambientes. 1.ed. Belo Horizonte: O Lutador, 2005. 272p.

SILVA, M.; HORN FILHO, N.O. Os depósitos tecnogênicos construídos no mapeamento geológico de planícies costeiras: o caso da Ilha de Santa Catarina, Santa Catarina, Brasil. Quaternary and Environmental Geosciences, v. 05, n. 2, p. 112-120, 2014.

VALE, T. F.; MOREIRA, J. C.; HORODYSKI, G. S. Geo-Food: uma nova perspectiva de preservação do patrimônio geológico. In: ENCONTRO NACIONAL TURISMO DE BASE LOCAL, 13., 2014, Juiz de Fora. Anais... Juiz de Fora: Universidade Federal de Juiz de Fora, p. 1-7, 2005. 